\title{
Preparedness for Disasters in Juntendo University Shizuoka Hospital
}

\author{
KAZUHIKO OMORI*, AKIHIKO KONDO*, KOHEI ISHIKAWA*, HIROMICHI OSAKA*, \\ YASUMASA ODE*, Youichi YANAGAWA*, Ken OKAMOTO* \\ *Department of Emergency Medicine, Shizuoka Hospital, Juntendo University, Shizuoka, Japan
}

\begin{abstract}
Currently, we are most afraid of a "megaquake", which may strike the Tokai, Nankai and East-Nankai regions simultaneously and trigger massive tsunamis. Located 3 kilometers inland and protected by two barriers, Juntendo University Shizuoka Hospital is not likely to suffer from tsunami damage. However, as a designated core hospital for rescue operations in Shizuoka Prefecture, we take disaster preparedness very seriously and engage in stockpiling supplies and training our staff. We also joined the Disaster Medical Assistance Team (DMAT). Our “Doctor Helis" were used most frequently after the Great East Japan Earthquake. Being a key player in the area, we conduct joint rescue training exercises with the fire departments in Eastern Shizuoka. This report briefly discusses the current issues and efforts being made to further prepare for future disasters.
\end{abstract}

Key words : disaster, DMAT (disaster medical assistance team), helicopter emergency medical service

\section{Introduction}

Faced with the 60 to $70 \%$ probability of major earthquakes hitting Japan's Pacific Coast within the next 30 years, preparedness for such catastrophic disasters is critically important (The Headquarters for Earthquake Research Promotion : Ministry of Education, Culture, Sports, Science and Technology, http://www. mext. go. jp/a_menu/hyouka/kekka/ 08100105/090.htm). Located three kilometers inland from Enoura Bay in Izu, Juntendo University Shizuoka Hospital is not vulnerable to direct tsunami hits. However, as the core hospital for helicopter-assisted rescue operations in the East Shizuoka area, our hospital is expected to play a key role in addressing any disaster/rescue issues. This article discusses our disaster prevention efforts, preparedness and the roles that our hospital would play in any future natural disasters.

\section{Looming earthquake and tsunami catastrophes}

Even before the Great East Japan Earthquake occurred on March 11th of 2011, Shizuoka Prefecture, where our hospital is located, feared the occurrence of a major earthquake. The most-feared disaster is the simultaneous occurrence of any two of the three major earthquakes forecast, namely, the Tokai, Nankai and East Nankai Earthquakes (Figure-1).

Major earthquakes historically recur every 90 to 150 years, with expected magnitudes of 8 to 9 on the Richter Scale. The Headquarters for Earthquake Research Promotion forecast that such a catastrophic earthquake would occur with a probability of 60 to $70 \%$ within the next 30 years. Tremors and tsunamis are estimated to kill a maximum of 400,000 people along the Pacific Coast of the country from Shizuoka to Kochi (on Shikoku Island). The estimated casualties in Shizuoka are 105,000 people including 96,000 tsunami victims, because most deaths in the Great East Japan Earthquake were a result of the tsunami.

Our hospital is located $3 \mathrm{~km}$ inland from Enoura Bay. If 39-meter-high waves, the highest waves produced by the Great East Japan Earthquake, hit

Corresponding author : Kazuhiko Omori

Department of Emergency Medicine, Shizuoka Hospital, Juntendo University, Shizuoka, Japan

1129 Nagaoka, Izunokuni-shi, Shizuoka 410-2295, Japan

TEL : +81-55-948-3111 E-mail : komichiwonasu@hotmail.co.jp

331st Triannual Meeting of the Juntendo Medical Society: Disaster Preparedness in Juntendo Hospitals 〔Held on Sep. 12, 2013〕

〔Received Oct. 28, 2013] 


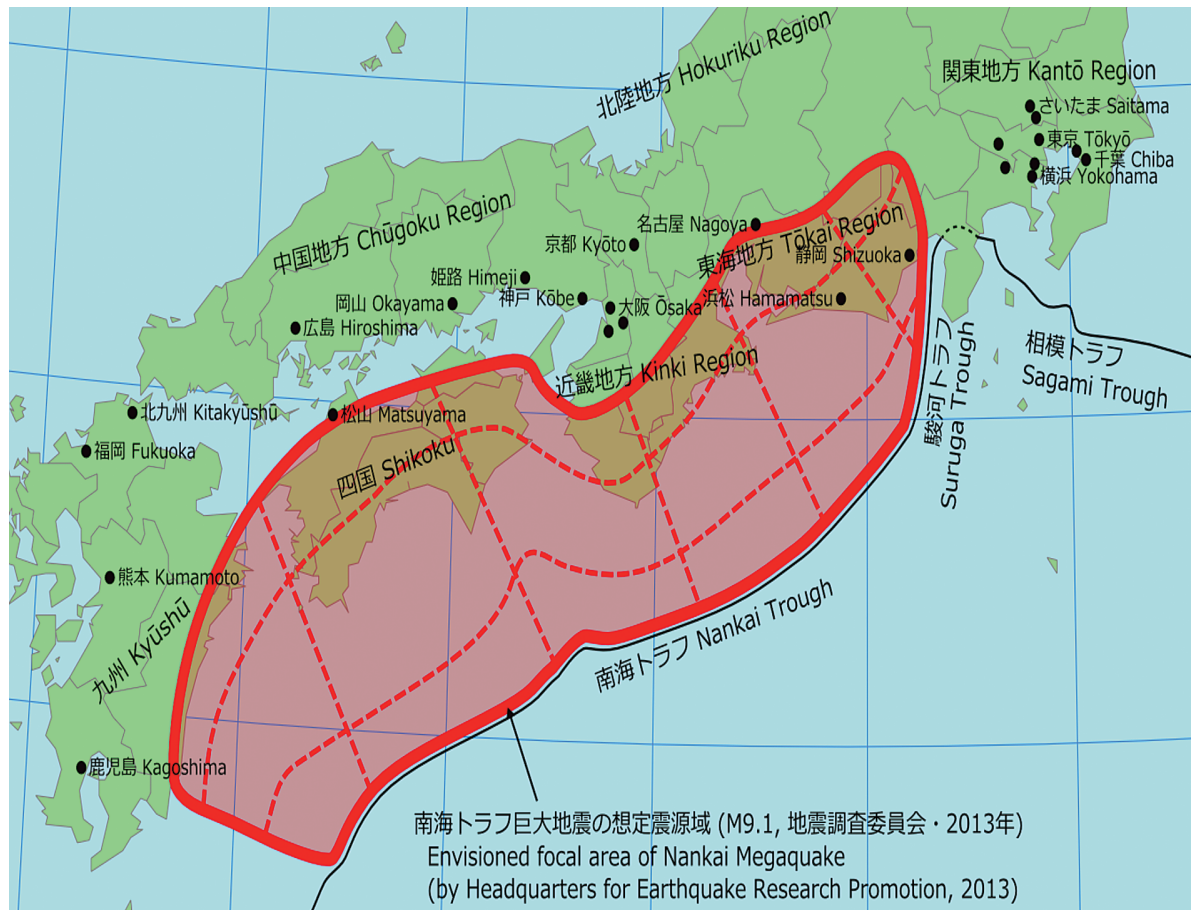

Figure-1 Fear of large future earthquakes, Tokai, Nankai and East Nankai megaquakes

Enoura Bay, the hill near the Kuchino Flood Control Canal, which has an altitude of 53 meters above sea level, would serve as the first barrier. A second barrier would be provided by the hill of Nagaoka Junior High School, which has an altitude of 82 meters above sea level. Unless tsunami waves greater than 100 meters in height hit the Pacific Coast, the Shizuoka Hospital area would be considered safe from tsunamis (Figure-2).

\section{Anti-disaster measures in Juntendo University Shizuoka Hospital}

Because some of the buildings in our hospital were not fully resistant to earthquakes, anti-earthquake renovations were carried out over a twoyear period, and all the buildings were made earthquake-resistant in April 2013. However, concerns about ground liquefaction and destruction of nearby bridges still exist. Such eventualities could cause the hospital to cut off from supply routes for three to five days. This necessitates the stockpiling of food, water and other supplies.

Anti-disaster measures for sudden interruption of lifelines are crucial ${ }^{1)}$. Our hospital has a reserve of 1,000 tons of water and $5 \mathrm{k} l$ of heavy oil for emergency power generation, air conditioning and boiler use. In terms of reserved food, we have a five-day supply of water and food for the 1,100member staff and 550 inpatients. We also have a one-day supply of food and water for 1,000 outpatients unable to return home. We have a three-day stock of medical supplies and equipment for treating external wounds and a one-week stock of non-emergency medical care and pharmaceutical supplies.

Electrical power is essential to maintain hospital function ${ }^{2)}$. Preparing for prolonged power outages, we increased emergency generators from six to eight in 2012. Consequently, our ability to operate examination equipment under power outage has remarkably expanded. While we were able to use one CT imaging machine and five portable $\mathrm{X}$-ray units and run only blood tests before equipment replenishment in April 2013, one MRI unit, one general X-ray machine and one DSA/CineAngio machine will now also be available under power outage.

\section{Historical review of Juntendo University Shizuoka Hospital}

Founded in April 1967, Juntendo University Shizuoka Hospital is located in Izuno-Kuni City in 


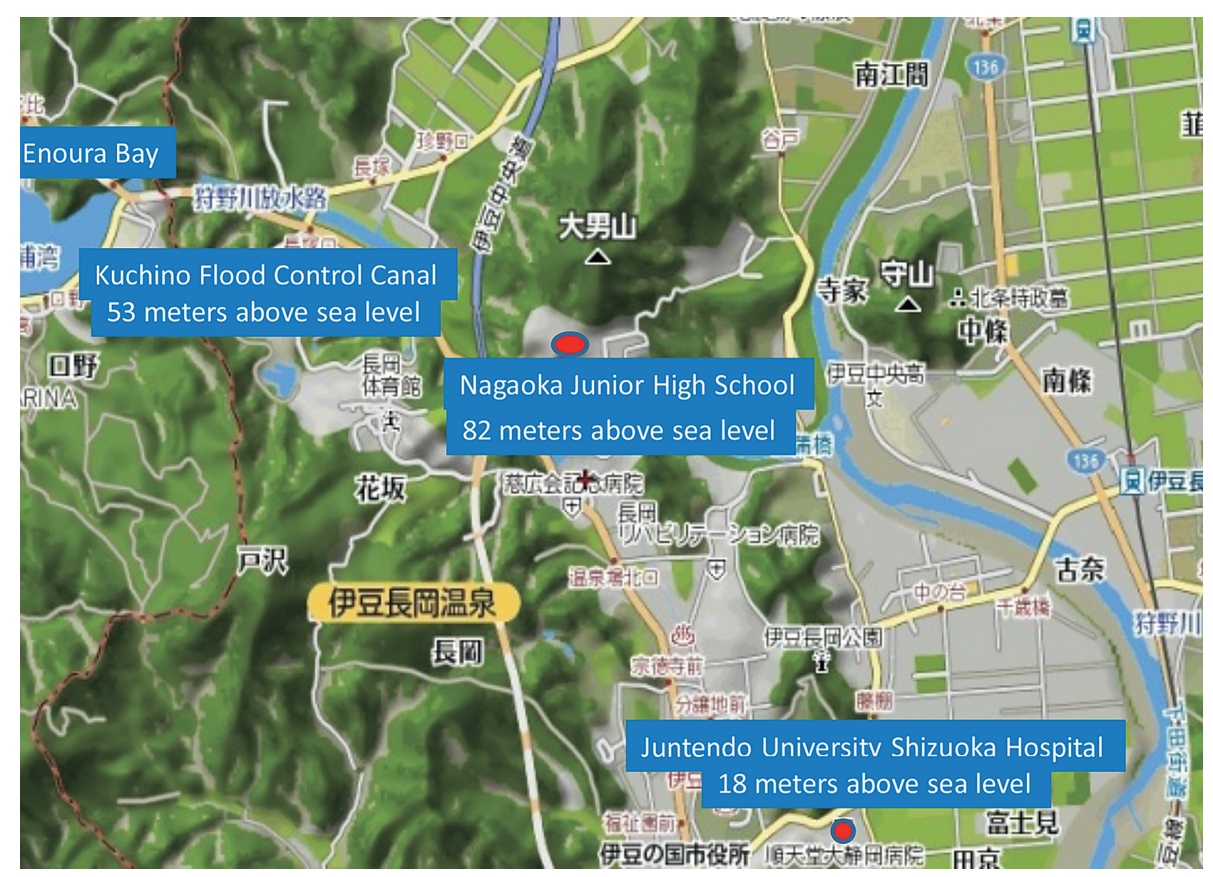

Figure-2 Our hospital is located 3km inland from Enoura Bay but is protected by two barriers

Shizuoka Prefecture. It houses 552 beds and is served by a 1,149-member staff (as of April 1st, 2013). In 2012, the average daily number of outpatient visits was 1,482 , and emergency arrivals that year totaled 13,747. According to the Ministry of Health, Labour and Welfare, Shizuoka Hospital ranked sixth in the nation in the number of critically ill patients admitted into the emergency medical care centers.

Our hospital opened its emergency care center on November 1st, 1981, and was designated as a Disaster Core Hospital in November 1996. Out of the 19 designated Disaster Core Hospitals in Shizuoka, the Shizuoka Prefectural General Hospital now serves as the foundation hospital. At our hospital, the first DMAT (Disaster Medical Assistance Team) was organized in April 2006, and a second team was added in May 2008. With these two teams currently operating, our hospital was designated as a DMAT hospital in Shizuoka in March 2012. Since March 2004, we have served as the core hospital for helicopter rescue operations manned with flight physicians (nicknamed 'Doctor Heli') for Eastern Shizuoka.

\section{Disaster simulation training programs}

The Disaster Contingency Committee at our

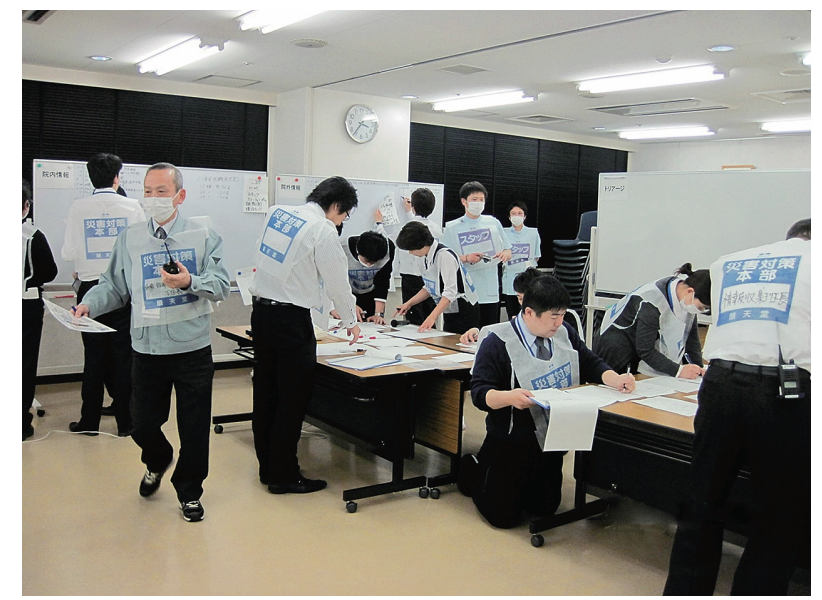

Figure-3 Large-scale hospital-wide disaster training

hospital meets every month to report on current activities and discuss the emergency manual and stockpiles/supplies. In February 2008, a large-scale hospital-wide disaster simulation training was carried out. Since then, disaster primary care seminars have been held every year, which have consisted of lectures on disaster triage and primary care, and practical training. In February 2012, a large anti-disaster training program, including lectures, was carried out. We did not experience any problems with primary care, as it is part of the hospital's daily routine, but problems cropped up when coordinating with the anti-disaster headquar- 


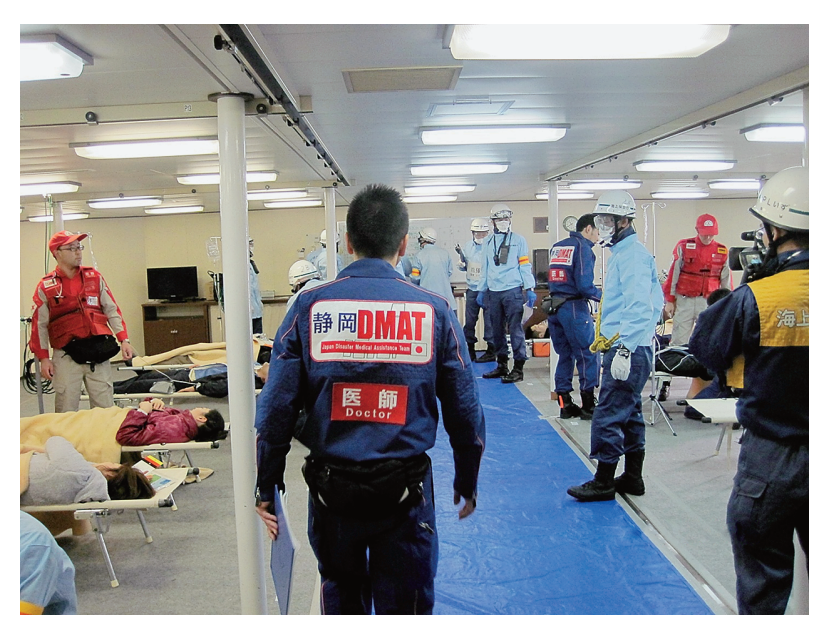

Figure-4 On-board triage operations on the patrol boat "Izu" of the Maritime Safety Agency

ters. This prompted us to conduct another large-scale training event in 2013, focused mainly on coordination and communication with the headquarters (Figure-3). Similar training should continue to be carried out regularly. Our hospital also holds fire drills every year, keyed to special issues/concerns.

\section{DMAT (Disaster Medical Assistance Team)}

The Juntendo Shizuoka Hospital DMAT, organized in April 2006, currently consists of six physicians, four nurses and three clerical workers, and can form two teams. In coordination with the prefectural government and other local organizations, our DMAT conducts two or three practical training events a year including wide-area medical transportations and SCU (staging care unit) operations in wide-area transport areas. In September 2013, the SCU headquarters was set up in Ashitaka Extended Park to serve the area and coordinate with the SCU headquarters of the Shizuoka Prefectural Government. This drill involved helicopters from the American Forces, Self Defense Forces and the Doctor Heli service. In February 2013, our team took part in aerial take-off/dispatch training for the first time. We boarded a prefectural government helicopter, landed on the patrol boat "Izu" of the Maritime Safety Agency, and subsequently conducted on-board triage operations inside the boat's care center (Figure-4).

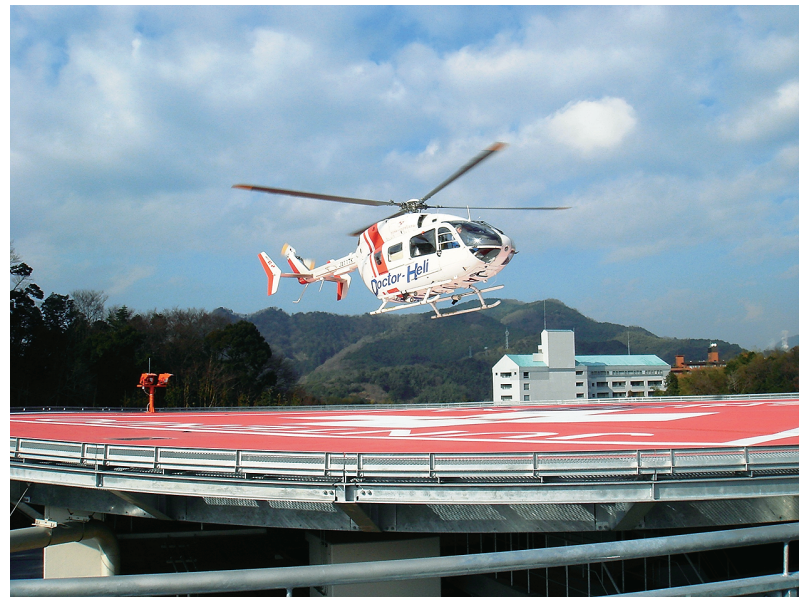

Figure-5 Eastern Shizuoka “Doctor Heli” headquartered at our hospital

\section{Helicopter emergency medical service and preparedness for disasters}

On the day of the Great Hanshin Awaji Earthquake, only one patient could be transported by helicopter. Subsequent reviews of initial responses to the catastrophic earthquake suggested that poor arrangements for aero-medical transportation systems in Japan might cause many preventable deaths. Therefore, the establishment of Doctor Heli services in Japan has been promoted since 2001. Ten years later, when the Great East Japan Earthquake occurred, many helicopters from the Self Defense Force and Doctor Heli services were used in the rescue operations, which proved that the arrangements for helicopter emergency medical service had been effective. In the aftermath of the Great East Japan Earthquake, 16 helicopters from 16 prefectures were immediately dispatched to the disaster-stricken areas and rescued the injured as well as hospital patients. Even in the first stage, at least 100 critically ill patients were said to have been transported.

As of May 2013, there are 41 Doctor Helis at 35 different locations in Japan. The East Shizuoka Doctor Heli Service, which uses our hospital as its base hospital, has been in operation since March 2004. In 2012, they were dispatched 640 times (Figure-5). Anticipating requests for Doctor Heli service in the event of disasters in Eastern Shizuoka, joint training has been conducted regularly with the local fire departments. 


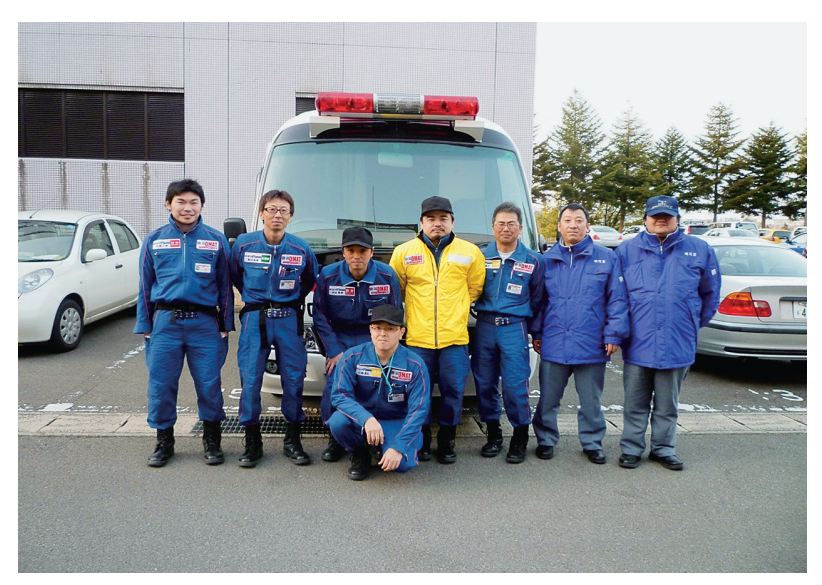

Figure-6 DMAT team at Juntendo University Shizuoka Hospital

\section{Shizuoka Hospital relief assistance after the Great East Japan Earthquake in 2011}

Immediately after the Great East Japan Earthquake struck northeastern Japan, our DMAT (Figure-6) consisting of 10 members departed from our hospital for Tsukuba, Northern Ibaraki and Fukushima in one Doctor Car (vehicle with a physician on board) and two ordinary sedans. From May 11th to 14th, 2011, the main work of our teams was to transport patients from the hospitals in hard hit areas to hospitals in safer areas. While many of other DMATs used ordinary vehicles. the Doctor Car that our DMAT used was extremely useful for medical activities in affected areas, because the vehicle is equipped with a respirator. From May 20th to 24th, 2011, six medical staff members from our hospital visited Iwate Prefecture as members of a medical backup team and worked at local clinics. Involvement in these rescue/relief operations taught us that rushing to a disaster site without adequate preparations could be ineffective, but this experience has improved our preparedness for future disasters.

\section{Conclusions}

In this article, we reviewed the risks facing us in future disasters, and the anti-disaster measures in Juntendo University Shizuoka Hospital. In order to play an adequate role as a Disaster Core Hospital, a DMAT hospital, and a hospital base for a Helicopter Emergency Medical Service in case of a disaster, adequate training and preparedness are very critical.

\section{References}

1) Nakajima $T:$ Disaster medical network for the patients with intractable disease-experiences of two large earthquakes. Rinsho Shinkeigaku, $2009 ; 49: 872 \sim 876$.

2) Hino H, Fukuyama T, Nakayama I : Electricity generators for disastrous emergencies. Masui, 2000 ; 49 : 448 449 . 